\title{
TECNOLOGIAS DIGITAIS DE INFORMAÇÃO E COMUNICAÇÃO (TDIC'S) E A SALA DE AULA
}

\section{Luzia Alves de Carvalho ${ }^{1 *}$ Shayane Ferreira dos Santos ${ }^{1}$ Layla Fernanda Pereira Oliveira ${ }^{2}$ \& Maria Eduarda Ribeiro Galdino ${ }^{3}$}

\section{RESUMO}

CARVALHO, L. A.; SANTOS, S. F.; OLIVEIRA, L. F. P.; GALDINO, M. E. R. Tecnologias digitais de informação e comunicação (TDIC's) e a sala de aula. Perspectivas Online: Humanas \& Sociais Aplicadas, v.9, n.26, p. 32-51, 2019.

Caracterizada por mudanças abruptas e radicais, motivadas em grande parte, pela incorporação das tecnologias digitais, a sociedade está mudando o mundo que conhecemos e no qual vivemos. Tecnologias disruptivas como a robótica, a Inteligência artificial, a realidade aumentada, a nanotecnologia, a biologia sintética, a internet thinking, sínteses da quarta revolução industrial exigem a reinvenção da educação, dos currículos escolares e dos processos de ensino e aprendizagem. Esses devem acompanhar os passos da mudança. Nesse sentido, fazse necessário que as escolas adentrem o universo das novas abordagens epistemológicas, das metodologias ativas, da cultura digital, da neuroeducação, entre outras que vêm exigindo professores competentes, atualizados e antenados com os novos tempos. Conforme a proposta inovadora do Centro Educacional Nossa Senhora Auxiliadora - CENSA, pensou-se em empreender essa pesquisa, cujo objetivo principal foi a formação das 17 professoras $^{2}$ do $6^{\circ}$ ao $8^{\circ}$ anos do Ensino Fundamental II, empoderando-as com novas metodologias e imersão na cultura digital, no período de um ano, agosto 2018 a agosto 2019. Foi um processo gradual, persistente, de muito estudo e acompanhamento da equipe docente. Com altos e baixos, os resultados mostram a formação de uma equipe coesa, comprometida com a mudança e engajada na proposta inovadora da Instituição.

Palavras-chave: Formação Docente, Tecnologias Digitais, Metodologias ativas, Inovação Metodológica 


\begin{abstract}
Characterized by abrupt and radical changes, and largely driven by the incorporation of digital technologies society is changing the world we know and we live in. Disruptive technologies such as robotics, artificial intelligence, augmented reality, nanotechnology, synthetic biology, and internet thinking, syntheses of the fourth industrial revolution require the reinvention of education, school curricula, and teaching and learning processes. These should follow the steps of changing. In this sense, it is necessary that schools enter the universe of new epistemological approaches, active methodologies, digital culture, neuroeducation, among others, which have required competent teachers

updated and tuned with the new times. According to the innovative proposal of the Centro Educacional Nossa Senhora Auxiliadora - CENSA, this research was thought, whose main objective was the formation of 17 teachers from 6th to 8th grades of Elementary School (Second Segment), empowering them with new methodologies and immersion in the digital culture, from one year, from August 2018 to August 2019. It was a gradual, persistent process of much study and monitoring by the teaching staff. With ups and downs, the results show the formation of a cohesive team, that is committed to change and engaged in the institution's innovative proposal.
\end{abstract}

Keywords: Teacher Training, Digital Technologies, Active Methodologies, Methodological Innovation.

\footnotetext{
${ }^{1}$ Institutos Superiores de Ensino do CENSA - ISECENSA - Laboratório de Formação de Professor - LAFORP - Rua Salvador Correa, 139, Centro, Campos dos Goytacazes, RJ, CEP: 28035-310, Brasil.

${ }^{2}$ Aluna Bolsista de Iniciação Científica PIBIC CNPq - Institutos Superiores de Ensino do CENSA - ISECENSA - Rua Salvador Correa, 139, Centro, Campos dos Goytacazes, RJ, CEP: 28035-310, Brasil.

${ }^{3}$ Aluna Voluntária de Iniciação Científica - Institutos Superiores de Ensino do CENSA - ISECENSA - Rua Salvador Correa, 139, Centro, Campos dos Goytacazes, RJ, CEP: 28035-310, Brasil.

(*) e-mail: luzia@censanet.com.br

Data de recebimento: 19/09/2019. Aceito para publicação: 13/12/2019
}

Persp. Online: hum \& sociais aplicada., Campos dos Goytacazes, 26 (9) 32-51- 2019 seer.perspectivasonline.com.br 


\section{INTRODUÇÃO}

Os primeiros resultados da pesquisa foram apresentados em dezembro de 2018 na UNIAMÉRICA, Foz do Iguaçu e publicados na revista Pleiade (htpss://pleiade.uniamerica.br/index.php/pleiade/article/view/450/575). $\mathrm{Na}$ ocasião, apresentamos o referencial teórico e os achados iniciais do trabalho realizado com as 17 docentes, objeto da Pesquisa. Até então, apresentei resultados que apontaram a efetivação de um processo inovador com passagem gradual de posturas acadêmicas tradicionais, para uma pedagogia sob novo enfoque: coragem para arriscar experimentar e aplicar metodologias ativas, games, vivência do hibridismo como princípio adotado pela Instituição. Para empreender essa inovação contou-se com acompanhamento direto da Direção Acadêmica e Supervisora Pedagógica, ambas membros da equipe pesquisadora, além de palestras, cursos, Workshop e atendimento individual ou em grupo das docentes.

Conforme afirmei em minha apresentação na UNIAMÉRICA e no $1^{\circ}$ relatório parcial da pesquisa, a Educação sofre mudanças sociais que impactam a vida escolar, os currículos, as metodologias, os tempos, espaços e circunstâncias. Essas mudanças interferem na vida das pessoas, nas relações entre elas, no mundo do trabalho e na escola. Novas abordagens revolucionam a educação e o ensino, acontecendo no bojo das condições sócio históricas da contemporaneidade, da qual nos fala Bauman (2001), gerando um clima de incertezas, medos, dúvidas e resistências. Estruturas rígidas e imutáveis desfazem-se exigindo de processos flexíveis, leves e adequados às novas aprendizagens, às habilidades e competências, necessárias ao cidadão do século XXI e à construção do novo perfil docente.

A ênfase na transmissão de conhecimentos e na memorização, contrasta-se com as novas abordagens pedagógicas, com foco nas competências cognitivas, pessoais e sociais, com processos colaborativos, personalizados, com alunos proativos, criativos e empreendedores. Urge portanto, pensar uma formação de docentes comunicativos, capazes de criar condições para que os alunos desenvolvam habilidades, competências e conhecimentos para enfrentarem os desafios da Quarta Revolução Industrial, já presente na contemporaneidade.

Mudanças radicais estão mudando o mundo, impulsionadas pelas tecnologias disruptivas: robótica, inteligência artificial, realidade aumentada, nanotecnologia, biologia sintética e internet thinking. A quarta revolução industrial cujos efeitos já sentimos, exige reinvenção da Educação e investimento na inovação, uma vez que o mundo está se reinventando a passos largos. Neste sentido a Agência IBGE de notícias (PNAD Contínua 2016) 4,2\% mostra que das pessoas que usam a internet para trocar mensagens de texto, voz ou imagem por aplicativos diferentes de e-mail. A motivação para assistir vídeos, programas, séries e filmes é $76,4 \%$ desse contingente, sendo que a conexão é feita por celular para $99,6 \%$ desse grupo. Quase dois terços da população mundial tem um celular e mais da metade do tráfego da web mundial vem de celulares, atestam dados do Digital, 2018. Sabe-se que 84\% dos internautas acessam diariamente a internet, em média, 9 horas por dia. Dos 210,1 milhões de brasileiros, 139,1 milhões são usuários da internet, com $66 \%$ de penetração; $62 \%$ são usuários de redes digitais, como se vê no infográfico.

Persp. Online: hum \& sociais aplicada., Campos dos Goytacazes, 26 (9) 32-51- 2019 seer.perspectivasonline.com.br 


\section{PERSPECTIVASonline}

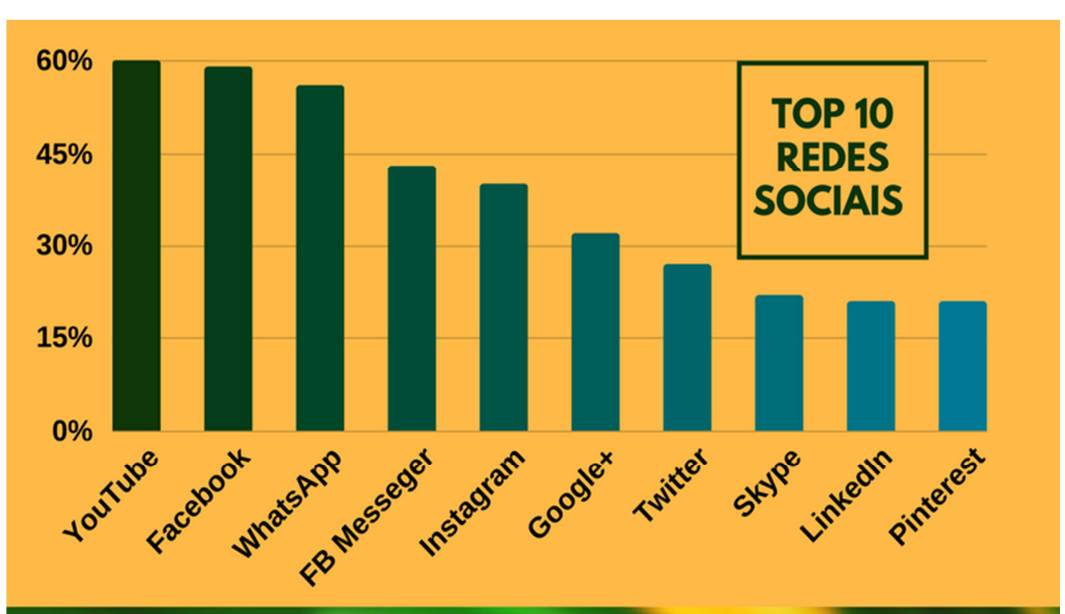

Figura 1: Infográfico sobre o uso de redes sociais via móbile. (Fonte: Infográfico internet Brasil. 2018).

Na nova geração digital, dificilmente se adapta aos velhos modelos de sala de aula, com ensino centrado no professor, provas e exames tradicionais. Experiências vivas de aprendizagem são as Metodologias Ativas potencializadas pelas tecnologias digitais.

Frente a essas considerações objetivamos, com esta pesquisa, a formação de 17 docentes do Ensino Fundamental II, do Centro Educacional Nossa Senhora Auxiliadora (CENSA), Campos dos Goytacazes-RJ, com o uso das Metodologias Ativas, potencializadas pelas tecnologias digitais da informação e do conhecimento (TDIC's) porque acreditamos que é possível uma nova escola que resulte em melhor aprendizado e mais prazer em estudar. Certo de que o aprendizado se faz em colaboração, o CENSA investiu na formação de sua equipe docente, buscando construir uma identidade institucional coletiva docente para formação de uma comunidade educativa coesa e antenada com as necessidades do mundo atual. Afirmei ainda, que a formação de professores é um processo inovador e colaborativo e para tal, exige a formação de professores capazes de empreender uma educação inovadora, disruptiva, antenada com os avanços da contemporaneidade.

A partir dessas considerações, fez-se a proposta de integrar inovações tecnológicas digitais e metodologias ativas no CENSA, visando ao desenvolvimento de habilidades essenciais aos estudantes do século XXI (SANTOS, 2018). Para implementar esse processo de inovação, o CENSA, partiu da convicção de que a formação de professores deve abarcar todas as docentes como um "coletivo social" onde cada uma desempenha seu "papel", em interação com o todo. (CARVALHO, 2009).

A ideia de "papel" está implícita na origem das instituições que tipificam os desempenhos, ações e modos de ação. Ela requer um sentido objetivo, que por sua vez, implica uma objetividade linguística, comum a todos. Conforme Berger e Luckann (2003, p, 101) "os indivíduos podem ser compreendidos como organizadores de ações objetivas, geralmente conhecidas, recorrentes e repetidas por qualquer ator tipificado". As ações incorporam-se à experiência do indivíduo por meio de papéis. É a partir delas que os educadores participam da vida acadêmica da instituição. Ao internalizá-las, o mundo objetivo torna-se subjetivamente real para elas. Pelo desempenho de papéis, docentes incorporam o ideário institucional.

Persp. Online: hum \& sociais aplicada., Campos dos Goytacazes, 26 (9) 32-51- 2019 seer.perspectivasonline.com.br 
Afirmamos ainda que (2003, p. 109): “a análise dos papéis permite chegar às raízes sociais macroscópicas da concepção de homem, mundo, educando, da instituição e do modo como elas se manifestam na consciência dos membros envolvidos e seu cotidiano". A própria instituição tipifica os atores individuais, construindo o sentimento de pertença como fator de coesão social e de unidade, o que abre caminho para inovações. Estas conduzem à formação de novos hábitos, atitudes, valores e maior expansão de terreno comum a todos os indivíduos. A posse dessa dimensão coletiva é o élan ou mística institucional, que contém as raízes de uma renovada ordem institucional, ou como afirmam Berger e Luckman (2003, p. 83-84), "um mundo social estará em construção, contendo nele as raízes da filosofia institucional em expansão".

Considera-se, portanto, que é fundamental mudar a escola, com novas metodologias que maximizem o potencial de aprendizagem dos alunos desenvolvendo-lhes as funções executivas, suas competências, habilidades e atitudes, pois todas as pessoas têm capacidade de criar e produzir ideias novas capazes de serem implementadas e gerar impacto (CAMARGO; DAROS, 2018).

A inovação que buscamos significa fazer o novo, alterar, acrescentar algo diferente ao já existente. Ela impulsiona as mudanças emergentes na sociedade contemporânea, que se transforma a ritmo exponencial, permeia todo o processo, desde a formação dos educadores, até as atitudes, ideias, culturas, currículo e práticas pedagógicas; suscita novas abordagens pedagógicas, novos modelos didáticos, novos projetos, tempos, espaços e ambientes escolares. Esta inovação parte do questionamento das finalidades da ação educativa e dos desejos dos sujeitos, dos meios necessários para que isto aconteça, segundo as necessidades da própria instituição educativa.

$\mathrm{O}$ uso de metodologias ativas associadas às tecnologias digitais, possibilitaram o processo inovador do CENSA. A combinação dessas metodologias ativas com tecnologias digitais móveis constituiu uma eficaz estratégia para inovação pedagógica (BACICH; MORAN, 2018). Para que se garanta este processo, deve-se contar com novos recursos tecnológicos e estruturas que possibilitem interação e novo modelo de formação docente (CAMARGO; DAROS, 2018). Elas permitiram a ressignificação da prática pedagógica, como possibilidade de ativar o aprendizado dos estudantes, ressituando-os no centro do processo, desviando o foco do docente para o estudante, com migração do ensinar para o aprender (SOUZA; IGLESIAS; PAZIN-FILHO, 2014).

\subsection{Metodologias Ativas impulsionam a Inovação}

Camargo e Daros (2018) ressaltam que metodologias ativas são necessárias para inovar as práticas pedagógicas em sala de aula. Esse ideário data de 1932, com a Carta Magna sobre a Escola Nova no Brasil que preconizava a aprendizagem, inserida no contexto. Seu mentor John Dewey, precursor da integração teoria-prática, propôs a aprendizagem a partir da realidade do aluno. Concebia a educação como reconstrução permanente das experiências do estudante com a vida.

Fundamentado nos princípios da escola ativa de Dewey, Kilpalrick (2015) introduz o método de trabalho com projetos, a partir de problemas do cotidiano dos alunos. No Brasil, Anísio Teixeira e Lourenço Filho adotaram os ideais de seus antecessores, contrapondo-os ao ensino tradicional, enfatizando a necessidade do protagonismo dos alunos na aprendizagem.

Persp. Online: hum \& sociais aplicada., Campos dos Goytacazes, 26 (9) 32-51- 2019 seer.perspectivasonline.com.br 
Desde os anos 1929, Decroly explicitava a necessidade de trabalhar com centros de interesse, mais adequados às necessidades e interesses dos alunos. Era uma forma de superar a fragmentação conteúdo-vida. Mais tarde, Ausubel (1976) propõe trabalhar os conhecimentos prévios dos alunos para uma aprendizagem coerente e significativa. Sua proposta, parte do princípio de que para aprender é preciso articular os conteúdos novos com os antigos.

Autores como Zabala (1998), Marzano e Pollock (2008) Mazur (2015) são referências para o estudo da aprendizagem ativa. Este último, professor de física em Harward, aboliu a transmissão de conteúdos em suas aulas gerando, mais tarde, o método peer instruction (aprendizado em pares) e flipped classroom (sala de aula invertida), muito conhecida hoje no Brasil. É significativo o ganho para os alunos, em termos de conhecimento e retenção de conteúdo, com o uso dessas metodologias em sala de aula. O infográfico mostra que $90 \%$ dos alunos, retém o conhecimento quando o praticam.

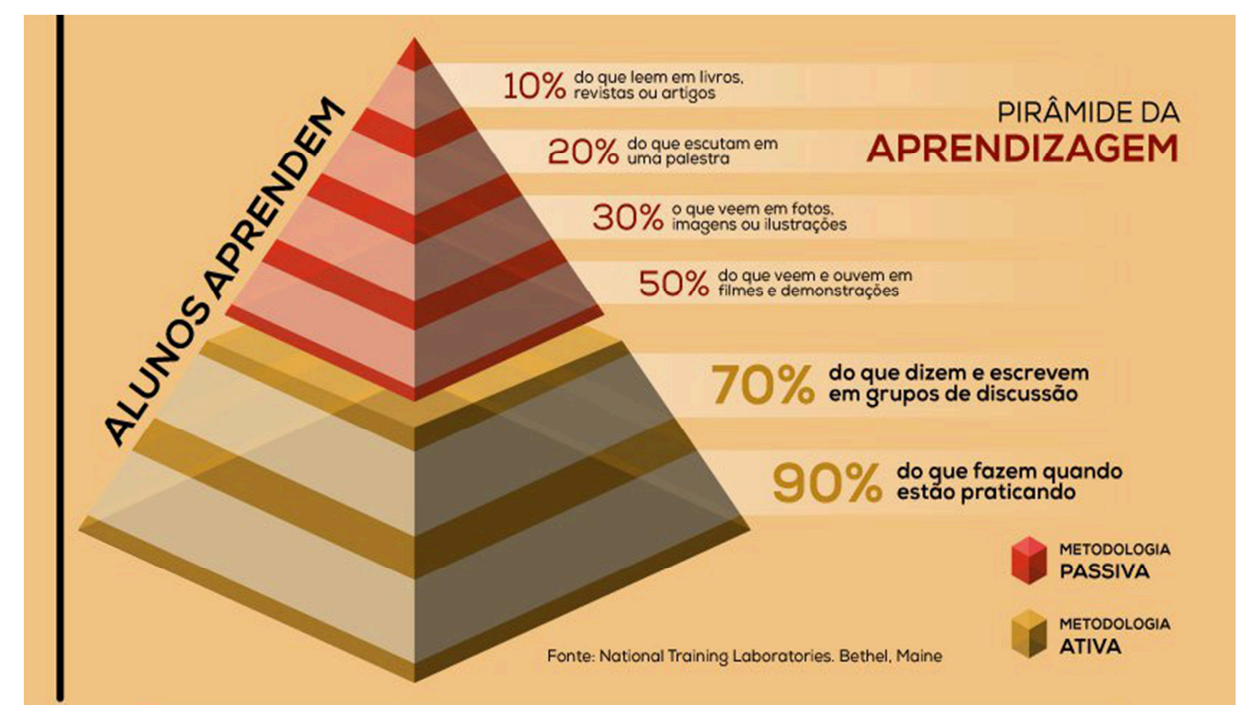

Figura 2: Pirâmide da aprendizagem. (Fonte: Disponível em

file://C:/Users/lcarvalho/Downloads/450-Texto\%20do\%20artigo-1491-1-1020190417\%20(1).pdf. Acesso em: 14 mar. 2019).

Estas considerações fazem crer que é preciso acelerar o processo de mudança, rever a sala de aula, o currículo, conteúdos e metodologias. A escola conteudista com alunos enfileirados, professor ditador de conteúdos, que ensina a todos, ignora a nova concepção de construção de conhecimento, que inclui competências cognitivas e socioemocionais aliadas à qualidade dos conteúdos; ignora igualmente que a educação convencional não mais responde à realidade dos alunos, sedentos de interatividade e participação.

Metodologias Ativas com tecnologias digitais permitem ensinar e aprender numa ligação simbiótica, profunda, constante entre o mundo físico e o digital, criando um espaço único em sala de aula ampliada, que se mescla e hibridiza; educação blended, misturada, híbrida, porque acontece não só na sala de aula, mas em múltiplos espaços, integrando o tradicional ao novo, com o uso das tecnologias digitais e da informação (MORAN, 2015).

O que se propõe com o ensino híbrido, assemelha-se ao que está acontecendo no sistema bancário, no comércio, nas empresas em geral (BACICH; NETO; TREVISANI, 2015). Nos anos 80, o sistema bancário vinculava o cliente à sua agência, na qual ela detinha o conhecimento de seus dados pessoais. Com a informatização do sistema bancário, o cliente

Persp. Online: hum \& sociais aplicada., Campos dos Goytacazes, 26 (9) 32-51- 2019 seer.perspectivasonline.com.br 
dispõe de um cartão que contém todos os seus dados, permitindo-lhe realizar transações em outras agências e/ou diretamente de sua casa. Atividades que cabiam aos agentes passam para os usuários com vantagens vieram para ficar. O trágico, é que a Educação é vagarosa em efetivar mudanças, que estão acontecendo lentamente e com pouca visibilidade. Essas, como em qualquer outro setor, não acontecem de maneira abrupta.

\subsection{TRAVESSIA}

Pessoas são motivadas por ideais, traduzidos em sonhos, materializados nos projetos e ações ao longo da vida. Em seu livro "Você é do tamanho dos seus sonhos", Souza (2003) desvenda a magia de sonhar e fazer acontecer, mostrando que todas as grandes ações são fruto do sonho de alguém, da sua emoção e imaginação. Para o autor, sonhar não é obra do acaso, requer gestos conscientes, visão clara de cenários; é inventar o amanhã.

O conteúdo dos sonhos é, invariavelmente, mais ou menos determinado pela personalidade individual daquele que sonha, por seu padrão de educação, estilo de vida e experiências acumuladas. Geralmente as pessoas sonham com as coisas que são objetos de suas paixões, cuja influência é preponderante nos sonhos. O homem ambicioso sonha com os lauréis que conquistou ou que ainda tem por conquistar. O apaixonado com o objeto de suas esperanças (FREUD, 1996). A relação entre este e a realidade, o significado do sonho, pode permanecer oculta por muito tempo. Tem que ser procurada diligentemente e, às vezes, só vem à luz muitos anos depois (CARVALHO, 2009).

Sonha-se com aquilo que é objeto das próprias paixões, com "pé no chão", para tornar realidade o significado do sonho. Por isso, o CENSA, com a equipe de docentes do Fundamental II, teoriza e prototifica o objeto de seu sonho expressando-o com o ensino permeado pelas metodologias ativas, e uso das tecnologias digitais da informação e do conhecimento em perspectiva híbrida.

Christensen, Horn e Staker (2015) ajudam a compreender o ensino híbrido a partir de dois tipos de inovação: a disruptiva e a sustentada, conceitos importantes para implantação de uma proposta híbrida de ensino nas escolas. Inovações sustentadas ajudam as instituições a criarem melhores produtos ou serviços e sustentarem seu movimento ascendente para melhorar o desempenho. As inovações disruptivas são mais profundas e radicais; introduzem novos benefícios no mercado, com maior simplicidade, e conveniência no uso e no custo. Elas impactam as empresas não preparadas para o diferente, empresas que vêm dando certo em seus negócios, que tem medo da mudança e de perder seus clientes tradicionais (CHRISTENSEN, 2015).

Em Educação, o ensino híbrido é uma opção de passagem, de inovação sustentada em relação à educação tradicional. Modelos híbridos, como aula invertida, aula por rotação e laboratório rotacional (BACICH; NETO; TREVISANI, 2015) estão numa trajetória sustentada em relação à sala de aula tradicional. Oferecem melhorias sustentadas em relação ao tradicional sem romper com ele. Os modelos disruptivos revolucionam o sistema escolar a longo prazo. Nas escolas, a opção sustentada pressupõe inventar uma solução híbrida que ofereça aos alunos o melhor do tradicional e do novo, combinando as vantagens de um e de outro modelo (CHRISTENSEN, 2015).

O CENSA optou pelo ensino híbrido como etapa de transição velho-novo, sem rupturas drásticas que afetassem o sistema educacional como um todo. Suas estratégias de

Persp. Online: hum \& sociais aplicada., Campos dos Goytacazes, 26 (9) 32-51- 2019 seer.perspectivasonline.com.br 
ensino consistem em uma sequência de situações possibilitadas e planejadas pelo docente ao longo de suas aulas, propiciando maior envolvimento dos alunos na construção do conhecimento, por meio novas práticas, colocando-os como sujeitos no processo de construção/aquisição, do conhecimento individual, grupal e tutorial. Essas estratégias auxiliam na superação da rigidez dos modelos mentais, possibilitando a flexibilidade cognitiva, a capacidade de raciocinar para solucionar diferentes problemas, contribuindo para o desenvolvimento do pensamento crítico e autônomo.

Este esforço é respaldado por Moran (2015) quando enfatiza a criação de desafios, atividades, jogos, recompensas estimulantes, que combinam percursos pessoais e grupais, com o uso de plataformas adaptativas, a partir das quais alunos e docentes aprendem com interações adequadas e uso de tecnologias digitais diversas.

Nessa perspectiva, Moran e Bacich (2018), seguindo o relatório Flipped Class Room Field Guide, sugerem projetos para inverter a sala de aula com atividades questionadoras, orientação para resolução de problemas, com material adequado ao processo ensinoaprendizagem. Nesse cenário, as atividades são voltadas para a produção colaborativa, na construção de saberes e significados, envolvendo também ferramentas diversificadas para a avaliação do processo. Os projetos podem variar em três vertentes: construtiva, investigativa e explicativa, mobilizando o desenvolvimento de habilidades e competências previstas na BNCC (2018). Elas implicam em atividades para motivação e contextualização, brainstorming (espaço para criatividade), atividades de planejamento, organização, execução, registro, reflexão da prática, apresentação, publicação dos resultados e materiais acessíveis aos alunos, para construir brincando, desmanchando, interagindo, colocando "a mão na massa". A gamificação introduz a linguagem e a lógica dos jogos em sala de aula, proporcionando aos discentes uma acentuada motivação e encantamento, porque adiciona elementos da realidade dos alunos, envolvendo desafios e fases, fantasias e descobertas, que geram aprendizagem significativa e prazerosa.

\section{METODOLOGIA}

Dando prosseguimento ao processo de inovação educacional que caracteriza o CENSA, optou-se por uma pesquisa para formação de seus professore, no período de agosto de 2018 a agosto de 2019 , com a equipe piloto composta por 17 professoras do $6^{\circ}$ ano ao ${ }^{\circ}$ anos do Ensino Fundamental II. Nesta ocasião, fez-se uma pesquisa exploratória com os professores de toda a escola sobre o conhecimento que detinham em relação às Tecnologias Digitais da Informação e do Conhecimento. Esses dados serviram de base para a atualização pedagógicadas docentes. Foi realizada por grupos de professores, segundo suas dificuldades e necessidades.

Em vista dos objetivos propostos tomou-se os resultados da pesquisa exploratória para conhecimento do campo e de seus sujeitos: os professores do Ensino Fundamental II e sua prática em sala de aula. A natureza do nosso objeto de investigação levou-nos a optar pelo paradigma qualitativo-etnográfico, considerando-o mais adequado ao nosso estudo.

A pesquisa etnográfica caracteriza-se por dispensar qualquer hipótese causal em relação ao objetivo estudado. Esse tipo de pesquisa etnográfica é, conforme Cunha (2002), um espaço de produção do conhecimento da vida diária, na qual os personagens interagem e os conhecimentos se interconectam, integrando teoria e prática, permitindo captar o contexto assim como ele é experimentado na complexidade do cotidiano e na riqueza que ele encerra.

Persp. Online: hum \& sociais aplicada., Campos dos Goytacazes, 26 (9) 32-51- 2019 seer.perspectivasonline.com.br 
Essas características permitem classificar esta pesquisa como "pesquisa intervenção" ou "pesquisa ação" porque as pesquisadoras fazem parte direta do processo como Diretora Acadêmica e Supervisora Pedagógica do CENSA, conduzindo o processo junto às professoras acompanhando-as no decorrer da pesquisa.

Como instrumento para coleta de dados utilizou-se, em $1^{\text {a }}$ instância, os dados coletados na $1^{\mathrm{a}}$ enquete sobre os pré-requisitos dos professores em estudo; os documentos do $1^{\circ}$ encontro com o CENSANET para formar parceria de apoio aos professores; os dados referentes aos encontros periódicos com professores e coordenadores sobre tecnologias digitais e metodologias ativas, anotações periódicas em cadernos de "observação participante" sobre práticas inovadoras das professoras, nas reuniões de estudos e acompanhamento da supervisão pedagógica.

A análise dos dados qualitativos foi feita pela técnica de "análise de conteúdo", tendo em visa à interpretação de material de caráter qualitativo, assegurando uma descrição objetiva, sistemática e com a riqueza manifesta no momento da coleta dos mesmos. Esta etapa exigiu mais atenção, mais tempo e mais perspicácia das pesquisadoras (MINAYO 2018), pois dela extraem-se os resultados e/ou considerações finais.

\section{RESULTADOS E DISCUSSÃO}

A coleta de dados feita a partir de questionários, observação participante, acompanhamento do processo vivido pelas docentes permitiu-nos chegar com sucesso aos resultados parciais da pesquisa, até dezembro de 2018.

Questionários aplicados às 17 professoras do Ensino Fundamental II do CENSA em agosto de 2018, para aferir-lhes conhecimentos básicos sobre informática mostrou-nos dados relevantes para percebermos a caminhada das professoras no processo educacional.

A Figura 3 ressalta que $47,1 \%$ das professoras demonstravam conhecimento completo desses fundamentos; $47,1 \%$, conhecimento parcial. O restante $5,8 \%$ conhecimentos básicos.

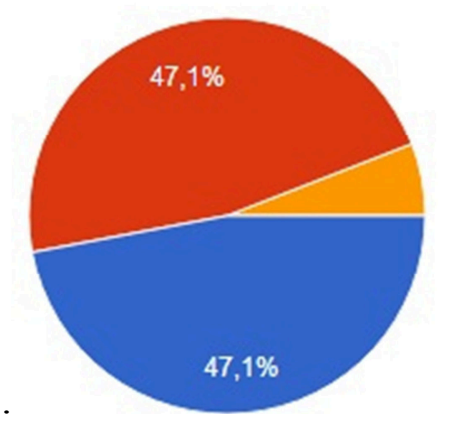

Completo

Parcial

Básico

Figura 3: Conhecimentos dos fundamentos da informática. Fonte: Elaboração própria / dados da pesquisa.

Resultados da Figura 4, a seguir, subsidiam a questão anterior em termos de competências necessárias ao uso da internet: aula, vídeos instrucionais, questão de provas, atividades de fixação, textos. Constatou-se que 52,9\% das docentes afirmam possuir domínio completo e $47,1 \%$ domínio parcial.

Persp. Online: hum \& sociais aplicada., Campos dos Goytacazes, 26 (9) 32-51- 2019 seer.perspectivasonline.com.br 


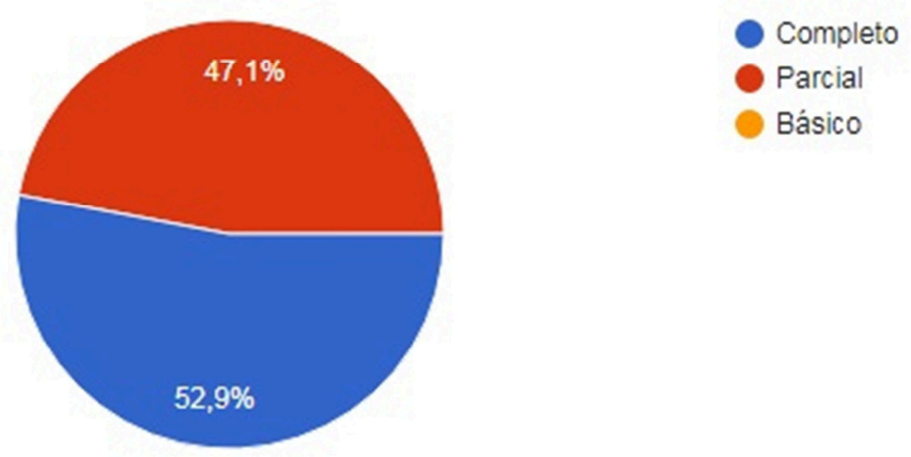

Figura 4: Domínio de recursos necessários ao uso da internet. Fonte: Elaboração própria / dados da pesquisa.

Confirmam-se os dados apresentados anteriormente e a necessidade de uma sólida formação das professoras, sobre as tecnologias e seu uso em sala de aula, considerando sua importância para à aquisição das competências e habilidades necessárias para os estudantes século XXI.

A análise dos resultados desses gráficos levou a intuir que as docentes não levam em conta a relação teoria e prática, e/ou conforme Bacich e Moran (2015), ignoram que o conhecimento (o que devem saber), deve ser mobilizado como uma competência: (O que se "sabe fazer" com "o que se sabe"), e ainda: "sem o saber, como mobilizar o saber fazer?". Para vivenciar a inovação da melhor maneira possível, deve-se colocar em ação a sinergia e os recursos cognitivos (PERRENOUD, 1999). Reafirma-se, pois, a necessidade de atualização das docentes em tecnologias digitais e sua importância na aprendizagem. Para isso foram organizados workshop e encontros pessoais para atender às docentes em suas necessidades específicas grupais ou pessoais para melhor atendimento aos estudantes, com aulas mais ativas, subsidiadas pelas TDIC's.

Cassiano Zeferino (2018 apud SANTOS, 2018, p. 25), reforça esse trabalho exortando: "educadores inovadores, devem possuir domínio dos meios para processo inovador que transcenda as visões pedagógicas clássicas, sem o qual, farão apenas visões isoladas baseadas no senso comum".

Horn e Staker (2015) corroboram a pesquisa, ressaltando a importância do ensino híbrido e, consequentemente das TDIC's. Ele é o motor para alimentar o ensino personalizado, baseado em competências. Assim como a tecnologia permite a customização de massa, o ensino online pode permitir que os estudantes aprendam em qualquer momento, lugar e ritmo, em larga escala. Necessita-se que as docentes percebam que as tecnologias fornecem aos estudantes um modo simples para chegar ao destino comum, liberando-os para que se tornem mentores, facilitadores, tutores, avaliadores e orientadores de ensino, para chegar a cada estudante de uma maneira antes impossível.

Em setembro as professoras foram questionadas, sobre "o quanto" usam as TDIC's em sala de aula (Figura 5). As respostas atestam que 58,8\% das docentes a utilizam sempre, $29,4 \%$ algumas vezes, $11,8 \%$ nunca.

Persp. Online: hum \& sociais aplicada., Campos dos Goytacazes, 26 (9) 32-51- 2019 seer.perspectivasonline.com.br 


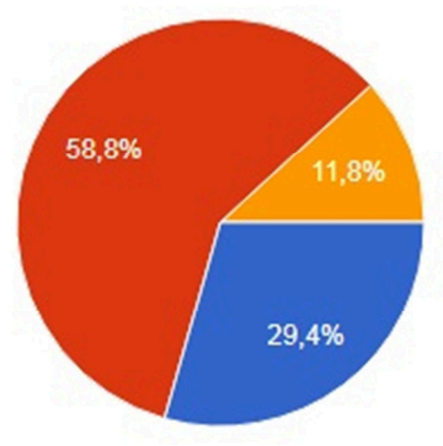

Não conheço

Figura 5: Utilização de ferramentas oferecidas pelos provedores de internet. Fonte: Elaboração própria / dados da pesquisa.

Infere-se certa resistência das educadoras para o uso das TDIC's, justificada pela falta de tempo, desconhecimento e muitas ocupações fora da escola, o que sugere desconhecimento da importância das TDIC's na aprendizagem, confirmando-se os resultados dos gráficos 01 e 02 . Os $11,8 \%$ das professoras que nunca as usam, são aquelas sobre as quais é preciso recair o cuidado e o acompanhamento das pesquisadoras e supervisora pedagógica do Ensino Fundamental II.

Subsidiando a análise, (HORN; STAKER, 2015, p. 83) afirma ainda: "se, simplesmente os educadores esperam que o futuro se torne presente, que novas formas de aprender entrem em cena, os acomodados continuarão com suas práticas tradicionais e pouca coisa vai mudar". É preciso que as docentes compreendam que os modelos de ensino híbrido são uma forma de inovação sustentada e visam atender melhor aos estudantes convencionais, em sala de aula tradicionais. As implementações das variedades sustentadas de ensino híbrido trazem melhorias vitais para a sala de aula tradicional. Canalizar os modelos sustentados para o seu mais alto potencial é uma prioridade importante e vantajosa dentro do sistema escolar.

Levantadas as defasagens das professoras fez-se, em outubro, outra atualização, por grupo de interesses e necessidades, enfocando aprendizagem colaborativa, gamificação, plataformas adaptativas, ensino híbrido e personalizado, em vista da melhoria do processo de produção, criação, acompanhamento e apresentação do que foi gerado em sala de aula, nesta ocasião os docentes desenvolviam projetos. Neste sentido, Moran e Bacich (2018, p. 168) afirmam:

Há um cuidado nos questionamentos, nas escutas, nas ações e intervenções junto aos professores. O desafio se mostra no momento de interpretar os dados. É costume provocar os participantes para pensar em suas próprias experiências. Esse momento costuma ser enriquecedor como aprendizado sobre a importância de construir uma solução partindo dos inputs do público-alvo. Este é um hábito que é preciso exercitar.

$\mathrm{Na}$ ocasião, novas metodologias ativas foram apresentadas e estudadas para sanar as lacunas que eram detectadas no grupo, como a aprendizagem por projetos e o Design Thinking. Estas tornaram-se objetos de estudo e trabalho realizado pelos estudantes do Ensino Fundamental II, em uma Semana Intercultural do CENSA, na qual eles desenvolveram projetos interdisciplinares sobre sustentabilidade, não violência, acessibilidade, preservação ambiental e direitos humanos.

Persp. Online: hum \& sociais aplicada., Campos dos Goytacazes, 26 (9) 32-51- 2019 seer.perspectivasonline.com.br 
Avaliações formativas, nos meses de outubro e novembro/2018, detectaram avanços, principalmente das docentes mais comprometidas com a mudança. Um questionário foi aplicado às docentes com uso do Software Survey Monkey, para averiguar-lhes a motivação e perceber se houve aumento no uso das TDIC's em sala de aula. Notou-se que docentes mais jovens, são mais motivadas e as usam ao menos uma vez por semana (78\%). Quanto aos motivos pelos quais $22 \%$ as usam raramente, apontou-se como causa, a desatualização, o que parece incoerente, considerando a oferta de treinamentos, cursos de atualização, mediações e acompanhamento constante ao grupo. As outras (50\%) consideram suficiente o que já fazem. Dado estranho para as pesquisadoras que acompanham o trabalho, mostrando às docentes caminhos e possibilidades para a integração de metodologias ativas no processo ensinoaprendizagem.

Pesquisa do CETIC, divulgada no "TIC educação 2018", aponta que 76\% dos docentes, utilizam internet para desenvolver ou aprimorar seus conhecimentos sobre o uso de tecnologias no processo de ensino aprendizagem. Entre os temas de interesse na busca de cursos e palestras, os mais citados são: uso de tecnologia em sua disciplina de atuação (65\%), uso de Metodologias Ativas (75\%) e formas de orientar os alunos para o uso de internet e celular (57\%). De acordo com a TIC Educação 2018, 90\% dos professores afirmam que aprendem sozinhos, com parentes, familiares e $82 \%$ procuram a ajuda dos pares.

Neste sentido as professoras do CENSA são privilegiadas, pois contam com apoio constante das coordenadoras, supervisora pedagógica e do serviço de apoio da escola. Recuos e deslizes das docentes não intimidam a equipe, mas sugerem uso de novas estratégias para trabalhar a autonomia intelectual das professoras mais vagarosas e/ou omissas, no exercício de sua profissionalidade, como compromisso e responsabilidade (BACICH; MORAN, 2018). Atenção especial com encontros pessoais, reforço, preparação conjunta de aulas, foi proporcionada às professoras para as quais o uso das tecnologias digitais em sala de aula ainda não é prioridade, mas que já se sentem incomodadas e interessadas em sair da zona de conforto.

Em dezembro de 2018 buscou-se saber que ambientes de aprendizagem (AVA) as docentes estavam utilizando. O Schoology, plataforma adaptativa, foi indicada por 15,38\% das docentes. Google Class por 23,08\%, Moodle por 7,69\% e outras por 38,46\%.

Persp. Online: hum \& sociais aplicada., Campos dos Goytacazes, 26 (9) 32-51- 2019 seer.perspectivasonline.com.br 


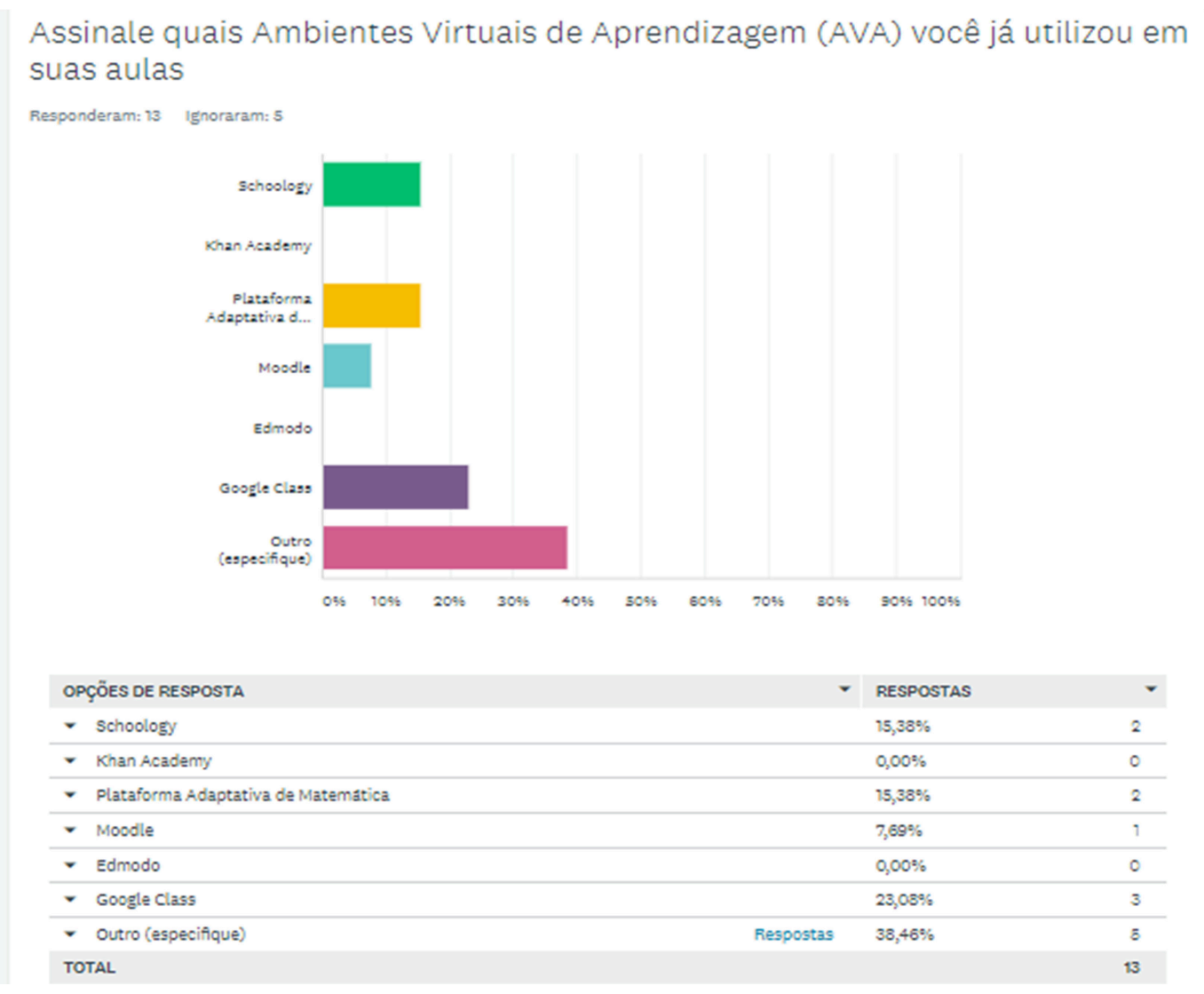

Figura 6: Uso dos Ava's em sala de aula. Fonte: Dados do APEI 50.

Comparando os dados obtidos com resultados de observação participante, percebe-se que as docentes mais atualizadas são as que mais usam as metodologias ativas como aprendizagem por rotação, sala de aula invertida, ensino personalizado, aprendizagem compartilhada, por tutoria, por projetos e gamificação.

Neste sentido, atesta Lúcia Dellagnelo (2019) que as plataformas adaptativas de aprendizagem são a grande inovação entre as práticas pedagógicas: à medida em que os alunos resolvem exercícios e identificam conteúdos que precisam ser reforçados.

Resultados mostram a importância do processo de apoio às docentes, a partir de acompanhamento contínuo, para que todas sejam empoderadas do valor das metodologias ativas potencializadas pelas TDIC's na aprendizagem dos estudantes.

Com o processo de acompanhamento, as docentes mostraram-se mais seguras, criativas assumindo os projetos de forma interdisciplinar, contextualizada, cooperativa e prazerosa, tornando-se aprendizes, condição necessária para novos tempos de rápidas mudanças, no qual o conhecimento e as habilidades tornam-se obsoletos como atesta Horn e Staker (2015). No aprender fazendo elas sentem-se mais seguras e realizadas.

Salto qualitativo foi dado pelo CENSA ao assumir em 2019, a cultura Maker como prioridade. Esta vem ganhando corpo na atualidade, como importante meio de aprender "fazendo". Foi estudada e divulgada com todos os docentes da instituição desde o período de atualização pedagógica, dezembro 2018 e fevereiro 2019. Essa atualização fez-se necessária para a maioria dos educadores, pois geralmente nas licenciaturas não se ensina o "como

Persp. Online: hum \& sociais aplicada., Campos dos Goytacazes, 26 (9) 32-51- 2019 seer.perspectivasonline.com.br 
fazer”. Esse novo passo é desafiador pois implica incorporação de uma nova cultura, um novo modo de ser e tornar-se professor.

A cultura maker ou "hand-on", com seus Fab Labs e Makerspaces surgiu no Brasil como estratégia inovadora promovendo a conexão teoria prática de modo efetivo. Os Fab Labs crescem como poderosa ferramenta de inovação, fundamentada no princípio: "faça você mesmo". Constituem uma das principais tendências da educação contemporânea, muito prazerosa para os alunos. As aulas, nesses espações, tornam os conteúdos mais significativos, porque são vividos e experimentados. Esta tendência valoriza a prática e a experimentação quando associada ao desenvolvimento de projetos. Implica em trabalho coletivo, estimula a criatividade, desenvolve a empatia, a autonomia, colocando o estudante como protagonista. Inclui resolução de desafios e busca de soluções para problemas emergentes da realidade.

Para trabalhar e incorporar a cultura maker o CENSA inaugurou um novo ambiente de aprendizagem, o MAKERSPACE CENSA, laboratório "mão na massa", um espaço colaborativo de inovação e criação. Foram realizadas oficinas para estudo e treinamento "Mão na massa", com a finalidade de oferecer aos estudantes e professoras novo espaço para uma aprendizagem mais significativa.

O conceito de Movimento Maker na educação, aprender fazendo, "mão na massa", tornou-se um fenômeno global, devido aos resultados observados a partir da incorporação desta metodologia com índices significativos de desenvolvimento e empenho dos alunos, em que são desenvolvidas habilidades de comunicação, conhecimento aprofundado, abertura ao feedback, reflexão, pensamento crítico e automatização. A propósito, afirma Marcos Garcia (2019): "a automatização do cotidiano das pessoas é uma ponta do iceberg." O foco é a oportunidade de o estudante de construir artefatos das mais variadas disciplinas, desenvolvendo a coordenação motora fina, a manipulação de ferramentas simples, programação de componentes a partir de códigos que instruem um robô ou sensor a executar funções específicas.

Para atender a essas finalidades o MakerSpace CENSA disponibilizou materiais e ferramentas necessárias desde o material básico como papéis de variados tipos, tinta guache, tinta 3D, cola quente e comum, palitos, canudos, caixas de lego comuns para montagens até caixa de lego para introdução à robótica e robótica avançada, impressora $3 \mathrm{D}$, data show, tela para projeção, mural com ferramentas de carpintarias, computador e 6 notebooks para aprendizagem de programação. O espaço dispõe, de mesas com cadeiras, murais para divulgação ou exposição de trabalhos e ideias, além de uma área para convivência com poltronas que possibilitam diferentes arranjos para planejamento e discussão de ideias, montagem de projetos, possibilidade de criação e mediação conforme ratifica Moran (2016) . O MakerSpace CENSA permite compartilhamento de experiências, tutoria de aprendizagem por imersão e oficinas para criação.

Nessa nova proposta, o acompanhamento dos projetos desenvolvidos faz-se necessário para orientação e ajuda às professoras resistentes à mudança e muitas vezes fixadas em seus velhos esquemas mentais. Romper e sair do próprio quadrado exige das docentes muito esforço e desejo de inovar. Aqui, o testemunho de quem arrisca o novo é "impulso" para aquelas que resistem pelo medo de errar. O medo romperia barreiras e bloqueia o desejo. A cultura Maker não se constrói de um dia para o outro; pode levar décadas para ser construída. Os primeiros passos bem sucedidos, são experiências possíveis e seus resultados são muito motivadores para os estudantes, pois favorecem à promoção das habilidades necessárias o

Persp. Online: hum \& sociais aplicada., Campos dos Goytacazes, 26 (9) 32-51- 2019 seer.perspectivasonline.com.br 
século XXI (BACICH, 2018), persistência, empreendedorismo, criatividade, cooperação, iniciativa com as docentes.

Após onze meses de trabalho formativo, investigou-se novamente, com questionário aberto sobre o uso das tecnologias e metodologias ativas na prática docente. Percebeu-se um avanço na compreensão das professoras sobre o significado de uso das Metodologias Ativas e TDIC's na aprendizagem. Dentre as 17 pesquisadas, 47,06\%, mostraram-se seguras e afirmaram utilizar as TDIC's e metodologias ativas "algumas vezes", o que é compreensível, considerando que nem sempre é preciso utilizar recursos digitais e que algumas vezes o espaço não está disponível nos horários desejados. Cerca de $17,65 \%$ delas sentem-se seguras e utilizam as TDIC's sempre que podem. Dado importante são os $35,29 \%$ que se sentem inseguras, e que apesar disso as utilizam mesmo com dificuldade, resultado considerado muito bom, em relação aos primeiros (gráficos 1, 2 e 3), pois, ainda que inseguras, as docentes arriscam implantar o novo, superando desafios e medos para aderir ao processo de inovação pedagógica da Instituição.

A este respeito, afirmam Horn e Staker (2015), que o futuro das escolas de Ensino Fundamental, é em grande parte, mas não exclusivamente, uma história de inovação sustentada para a sala de aula, lembrando-se que alguns modelos de ensino têm todos os sinais de uma inovação sustentada híbrida. Eles prometem melhoria para às salas de aulas tradicionais, mas não uma ruptura, pois os modelos são disruptivos em relação salas de aula tradicionais. Uma sala de aula convencional, se hibridiza com o Modelo de Rotação que compreendendo: Rotação por Estações, Laboratório Rotacional, Sala de Aula Invertida. O Ensino Online disruptivo, compreende os modelos Flex, à La Carte e Virtual Enriquecido.

Esse trabalho de inovação no CENSA vem gerando conhecimento sobre o uso das Metodologias Ativas e TDIC's na formação contínua de professoras. Segundo depoimento dos estudantes: "as aulas através de desafios e disponibilidade de diferentes espaços de aprendizagem, aumentou nosso interesse e deixou-nos curiosos frente aos QR codes e uma proposta gamificada".

Analisando apenas o $1^{\circ}$ semestre de 2019, como um todo observou-se que o celular, tablet e computador, laboratórios foram utilizados por todas as docentes para investigação, reflexão e análise de fatos, dados e fenômenos, desenvolvimento de habilidades linguísticas , compreensão, elaboração de relatórios, mobilização de práticas de cultura digital, uso de diferentes linguagens, reflexão sobre o mundo, elaboração de enquetes, análise cartográfica e de recursos estilísticos, semióticos e de gênero; compreensão de conceitos e estruturas explicativas das ciências e fatos históricos, das relações de poder e mecanismo de transformação e manutenção de estruturas sociais, políticas, econômicas e culturais, elaboração de vídeos, composição de histórias em quadrinhos, utilização de aplicativos para revisar conteúdos, resolver problemas de naturezas diversas, elaboração de textos multimodais, organização de quizzes, leitura de QR code.

A adoção desses recursos e o trabalho por habilidades e competências é referendada pela BNCC (2018): para introduzir a tecnologia em sua didática é necessário que as docentes sejam preparadas desde a graduação. Assim, poderão ensinar aos discentes como manter sua individualidade e exercer a cidadania digital, que é o uso responsável e consciente da tecnologia.

Persp. Online: hum \& sociais aplicada., Campos dos Goytacazes, 26 (9) 32-51- 2019 seer.perspectivasonline.com.br 
Para aferir com precisão os possíveis avanços e a posição real das docentes no processo ensino-aprendizagem na Instituição, buscou-se um instrumental que possibilitasse isenção nos julgamentos dos envolvidos na pesquisa, pessoas imersas no cotidiano do CENSA. Optou-se pelo APEI 50, um programa de Avaliação das Práticas Educacionais Inovadoras, criado pelo Instituto Crescer de São Paulo. Esse programa tem como objetivo avaliar o grau de inovação pedagógica de uma Instituição Educativa, colaborar com o desenho de estratégia de intervenção, envolvendo investimento em tecnologias digitais e formação docente, fomentar discussões que permitam avançar rumo a uma nova Educação. Pressupõe que a Instituição tenha seu planejamento estratégico com políticas de inovação em educação numa missão claramente definida, baseada no perfil dos estudantes, alinhamento pedagógico, metodologias e tecnologias. $\mathrm{O}$ instrumento escolhido é composto por um questionário de 50 questões a partir de 3 pilares que analisam: usabilidade, com 17 questões ou itens de teste ( 1 a 17); competências socioemocionais com 11 itens (18 a 28); competências digitais com 13 itens ( 29 a 41$)$ e 9 itens ( 41 a 50) finais sobre competências docentes.

O pilar usabilidade refere-se ao uso eficaz das tecnologias digitais em estratégias pedagógicas e mensuram o potencial dessas tecnologias para fomentar o desenvolvimento das competências para o século XXI. As competências digitais refletem a capacidade de o corpo docente atualizar e inovar o contexto educacional. As competências socioemocionais avaliam atitudes e valores que devem constituir o profissional como pessoa e cidadão ético e contextualizado (BNCC, 2018; PPC, 2017). As competências docentes referem-se à capacidade de conduzir o processo de ensinar.

Todos os indicadores permitem a escolha de um entre quatro parâmetros possíveis de resposta, elencados a seguir (CRESCER, 2019):

- Objetivo atingido (OA), quando a ação em questão faz parte da rotina docente e discente.

- Objetivo parcialmente atingido (OPA), representa que algumas vezes o professor trabalha de acordo com o que está sendo exposto e vê o resultado na aprendizagem dos alunos;

- Objetivo não atingido (ONA) representa que a situação não faz parte da prática docente ou que não vê resultado incorporado pelos alunos;

- Não se aplica (NA) representa que a ação em questão, nunca fez parte da prática pedagógica.

Para realizar a avaliação com instrumental APEI 50, as docentes foram orientadas sobre a reflexão que deveriam fazer para selecionar o melhor parâmetro. O resultado geral, mostrou o perfil das professoras do CENSA, que permitirá traçar um plano de ação para que a Instituição avance rumo a uma educação de qualidade, mais prazerosa para os alunos.

A Figura 7 mostra que as docentes do Fundamental II situam-se no nível intermediário, com variações na escala de 1 a 4 . Esse resultado é satisfatório, considerando os percentuais bem próximos do máximo previsto, 4.

Persp. Online: hum \& sociais aplicada., Campos dos Goytacazes, 26 (9) 32-51- 2019 seer.perspectivasonline.com.br 


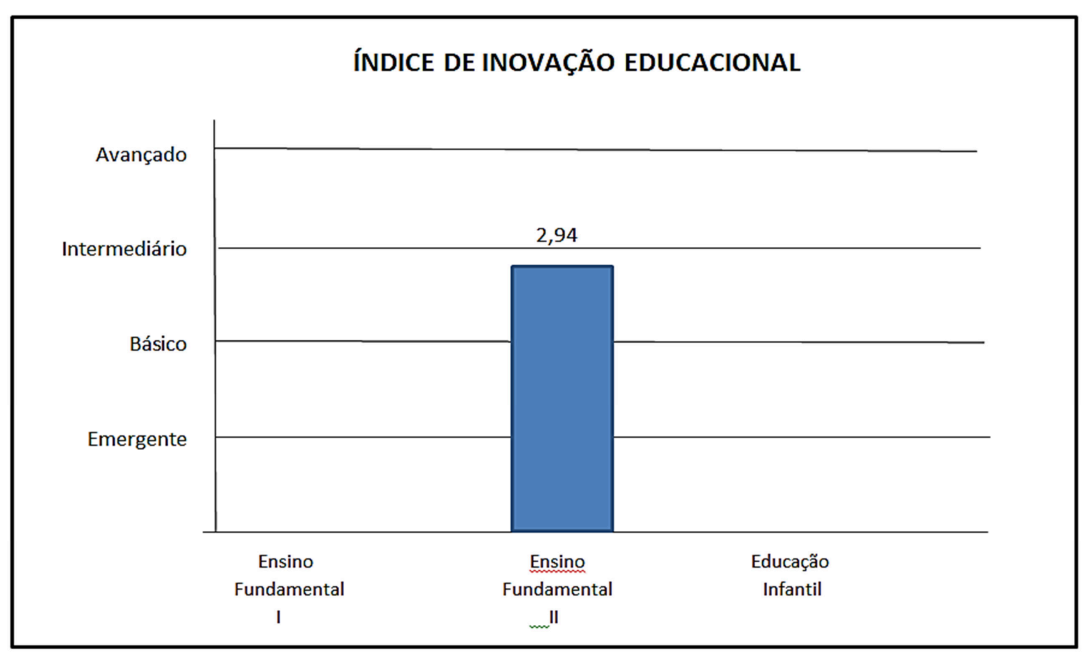

Figura 7: Índice de inovação Educacional. Fonte: Dados do APEI 5

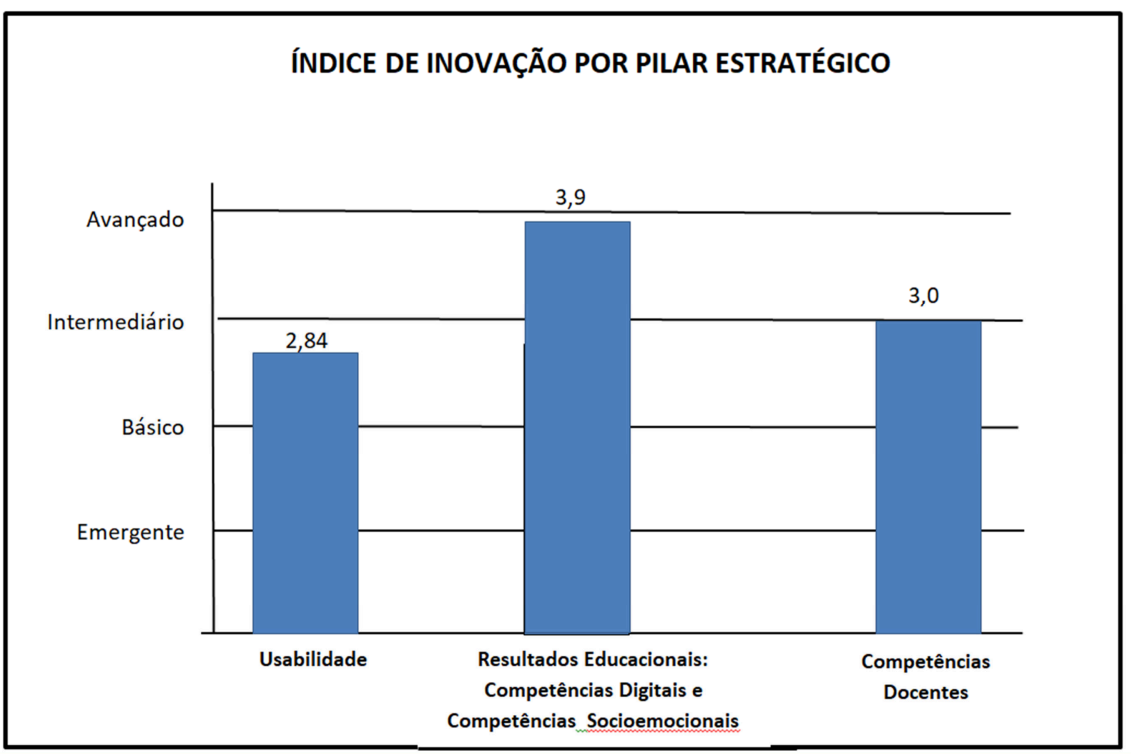

Figura 8: Índice de inovação por pilar estratégico. Fonte: Dados do APEI 5.

A Figura 8 mostra que o resultado das professoras foi muito bom em competências educacionais, devendo, entretanto distinguir o resultado das competências digitais do resultado das competências socioemocionais. Nestas, as professoras demonstraram desempenho elevado. Isto é particularmente importante para o CENSA, considerando-se que sua proposta pedagógica centra-se no humanismo cristão do fundador da Instituição Salesiana, Giovanni Bosco (PPP CENSA, 2018). Sua pedagogia centra-se no valor da pessoa humana e na prática docente centrada nos três pilares: Razão, Religião e Amorevollezza, entendida como amabilidade, amizade, cuidado, acompanhamento.

É, particularmente, importante ressaltar que o trabalho do corpo docente do Fundamental II do CENSA, está afinado também com a BNCC, ao destacar as habilidades e competências socioemocionais (BNCC, 2018). Uma análise pormenorizada dos pilares sob o ponto de vista dos Objetivos, mostra, que no total de 800 questões respondidas por 16

Persp. Online: hum \& sociais aplicada., Campos dos Goytacazes, 26 (9) 32-51- 2019 seer.perspectivasonline.com.br 
professoras, 272 referem-se à Usabilidade, 176 Competências Digitais, 208 Competências Socioemocionais e 144 Competências Docentes.

Sob o enfoque dos objetivos, no quesito de Usabilidade, foi notado que, desses 272 itens respondidos, 68 Objetivos Atingidos (25\%); 109 Objetivos Parcialmente Atingidos (40\%); 90 Objetivos Não Atingidos (33\%; 5); 5 Não se Aplicam (20\%). Se considerarmos o Objetivo Atingido e Objetivo Parcialmente Atingido, juntos, tem-se um percentual $(65 \%)$ indicando que as professoras se empenham ainda pouco no uso das tecnologias em sala de aula, ganho razoável em termos de estudo e interesse, quando esse dado foi comparado com os gráficos de 1 a 4 . O acompanhamento e empenho da supervisão pedagógica e pesquisadores devem prosseguir junto às docentes para torná-las mais proativas no uso das tecnologias no exercício cotidiano da Prática Pedagógica.

Quanto aos resultados educacionais, OA e OPA, observou-se em "competências digitais", as professoras alcançaram um patamar de 67,6\%. Esse é um resultado que deve ser levado em conta considerando que as docentes desse segmento, não são nativos digitais e que apresentaram em todo o processo da pesquisa, dificuldades, resistências e esforço de adaptação a inovação das práticas pedagógicas. Estas competências precisam ser trabalhadas para que se tornem uma segunda natureza para as professoras. Quanto às competências docentes, nível 3, percebe-se que o resultado elevado advém do processo de formação de professores muito valorizado na escola. Ressalta-se que as docentes tiveram dificuldade ao responder ao questionário por desconhecerem os conteúdos das questões; acredita-se, que se aplicado em dezembro de 2019, as respostas serão mais fidedignas.

Vencer resistências e barreiras foi um processo doloroso. Sair do status quo, deixar o seu quadrado, arriscar o novo, quebrar preconceitos, medos, acreditar em si mesmo e na própria capacidade de mudança foram passos necessários para adentrar na cultura digital (BACICH; MORAN, 2018).

\section{CONCLUSÕES}

A análise e discussão dos dados e resultados trouxe à tona avanços, percalços e desafios no processo de inovação empreendido pelo CENSA para formação de sua equipe docente do Ensino Fundamental II, com Metodologias Ativas e Tecnologias Digitais.

Mudanças significativas aconteceram na prática das docentes com uso mais frequente dos ambientes virtuais de aprendizagem (AVA), desestruturando e reconstruindo modos de fazer, reconceitualizações e ações, vencendo insegurança, medos, arriscando "aprender fazendo" e aprender a aprender em comunidade.

Bauman (2001) consolida a pesquisa ao caracterizar a condição histórica com a liquidez que gera insegurança, medo, dúvidas e resistências. Nesse contexto de muito estudo, tentativas, realizações, vêm quebrando a solidez e segurança das docentes, as estruturas rígidas e fixas do CENSA, estruturas que se desfazem frente à nova proposta de uma abordagem híbrida dos processos de ensino aprendizagem. A abordagem tradicional do CENSA que privilegiava a ênfase nos conteúdos, avaliação padronizada, aferida por critérios rígidos, fora do contexto real dos estudantes, muda o foco para o desenvolvimento de processos colaborativos, personalizados, em vista dos alunos proativos, criativos e empreendedores, segundo os princípios da BNCC (2018).

Persp. Online: hum \& sociais aplicada., Campos dos Goytacazes, 26 (9) 32-51- 2019 seer.perspectivasonline.com.br 
Neste sentido, pôde-se constatar uma mudança na prática de cada professora, ressaltando seu esforço, empenho para aprender e aplicar as Metodologias Ativas em sala de aula, com uso de tecnologias digitais, em ambientes virtuais de aprendizagem e em espaços diferenciados conforme relatórios periódicos de observação da prática. Cada docente se desinstalou à sua medida, desejosa de arriscar o novo e, de algum modo, participar de sonho comum de uma escola que se inova a cada dia; sonho que segundo Carvalho (2009, p. 123) "deve transcender os espaços escolares rígidos, desmotivadores, com a busca de outros mais personalizados, geradores de pessoas criativas, vivas, antenadas com o novo, o diferente, o disruptivo que ainda está por vir.”

Houve resistências, medos, acomodações, inseguranças, incerteza quanto aos resultados, atitudes bloqueadoras no processo de inovação. Essas barreiras estão cedendo lugar à curiosidade e desejo de aprender fazendo em busca de inovação. Professoras proativas e dinâmicas desafiam ainda aquelas temerosas, cientes de que é possível arriscar por uma causa comum, concretizar o sonho coletivo de uma escola de qualidade, antenada com os tempos, lugares e circunstâncias.

Não há dúvidas de que toda inovação é um desafio, pois desinstala, exige quebra de paradigmas, saída da zona de conforto, disponibilidade para atualização, para criar estratégias e buscar recursos, esforço para adaptá-los aos conteúdos, mobilizar discentes, deixar para trás esquemas rígidos, inibidores, geradores de práticas estereotipadas e desinteressantes.

Considerando os objetivos da pesquisa, evidenciou-se o processo percorrido pelas docentes no uso de metodologias ativas e TDIC's em sala de aula. Processo que resultou em salto qualitativo para a organização com realização de aulas dinâmicas, interativas, geradoras do protagonismo e formação de estudantes críticos e criativos, comunicativos, atores de suas aprendizagens com domínio de habilidades de estudo, afetivas e sociais, como é proposto na BNCC (2018).

Quanto às docentes, percebe-se mais integração entre elas, esforço de adequação aos novos tempos, às iniciativas da instituição, na busca da travessia para um sistema de ensino híbrido com uso de metodologias ativas e TDIC's.

Pode-se dizer que o germe da constituição de uma identidade institucional coletiva entre as docentes está surgindo, como resultado de um trabalho integrado, cooperativo, participativo, continuamente motivado, articulado, incentivado e incrementado com encontros pessoais, grupais, workshop, cursos, palestras, discussões e experimentações.

O entusiasmo das professoras e suas realizações bem sucedidas não são fogo fátuo, porque, centrado "na" e "pela" reflexão da prática, na esperança de aceitar o risco de olhar para a frente, se ultrapassar e não se limitar ao momento presente e suas seguranças (CARVALHO, 2009). Assim, as docentes evidenciaram seu sentido de pertença (BERGER; LUCKMANN, 2003) construindo coletivamente outro imaginário pedagógico, orientadas para um futuro em que os discentes estudem com prazer e aprendam com autonomia, proatividade e solidariedade.

Para que o projeto de inovação tenha êxito, sugere-se que o processo continue com estudo de novas práticas e abordagens pedagógicas, avaliação contínua individual e grupal, socialização das experiências, transformadas em publicações em cursos e congresso. Importa incentivar, estimular, nunca desistir, corrigir segundo as necessidades das docentes e elogiar

Persp. Online: hum \& sociais aplicada., Campos dos Goytacazes, 26 (9) 32-51- 2019 seer.perspectivasonline.com.br 
todo esforço empreendido.

No desempenho competente, as docentes, imbuidas de seu papel, como profissionais responsáveis, incorporaram o ideário da Instituição construindo o sentido de pertença, como o elan, raiz de uma nova visão educacional, que não é modismo, mas convicção de que novos tempos estão por vir, abrindo horizontes. Acredita-se que as docentes saiam mais fortalecidas em suas convicções, mais renovadas e desejosas de mostrar que são capazes de empreender o novo.

A certeza do "ainda não" e do "que pode vir a ser" é a tensão contínua que tecerá no tempo a profissionalidade contextualizada, crítica, cooperativa, original e inacabada dessas professoras. O sonho é um devir e depende do impulso que lhe for dado. Ele está nas mãos de cada professora, dessas identidades plurais, originais, inacabadas, em "se fazendo", a cada momento (CARVALHO, 2019).

A modo de conclusão recorremos a Guimarães Rosa (1979): "O senhor" mire e veja... o mais importante e bonito, do mundo é isto: que as pessoas não estão sempre iguais, ainda não estão terminadas, mas vão se mudando".

\section{REFERÊNCIAS}

ALVIRA, F. R.M. et al. Los dos métodos de las Ciencias Sociales. Madrid: Centro de Investigaciones Sociológicas - CIC, 1979.

ANDRÉ, M. et al. Estado da arte da formação de professores no Brasil. Revista Educação e Sociedade, Campinas: SP, v. 68, n. especial, p. 301-309, 1999.

AUSUBEL, D.P. Psicología educativa: um punto de vista cognoscitivo. México, Editorial Trillas. Traducción al español de Roberto Helier D., de la primera edición de Educational psychology: a cognitive view, 1976.

BACICH, L.; MORAN, J. Metodologias ativas para uma educação inovadora: uma abordagem teórico-prática. Porto Alegre: Penso, 2018.

BACICH, L.; NETO, A. T.; TREVISANI, F. M. (org.) Ensino híbrido: personalização e tecnologia na educação. Porto Alegre: Penso, 2015.

BAUMAN, Zygmunt. Modernidade líquida. Rio de Janeiro: Jorge Zahar, 2001.

BERGER, P.; LUCKMANN, T.A. Construção social de realidade: tratado de sociologia do conhecimento. Tradução Floriano de Souza Fernandes. 23. ed. Petrópolis, Rio de Janeiro. Vozes, 2003.

BRASIL. Base Nacional Comum Curricular: documento completo. Brasília: MEC/Secretaria de Educação Básica, 2018. Disponível em: http://basenacionalcomum. mec.gov.br/images/BNCC_EI_EF_110518_versaofinal_site.pdf. Acesso em: 11 maio 2019.

CAMARGO, F.; DAROS, T. A sala de aula inovadora: estratégias pedagógicas para fomentar o aprendizado ativo. Porto Alegre: Penso, 2018.

CARBOnELL, J. Pedagogias do século XXI. Porto Alegre: Penso. 2016.

Persp. Online: hum \& sociais aplicada., Campos dos Goytacazes, 26 (9) 32-51- 2019

seer.perspectivasonline.com.br 
CARVALHO, L.A. et al. Formação de Professores: Implementação de Práticas Inovadoras em Sala de Aula. Pleiade, 12(25): 64-78, Dez., 2018. Edição Especial VI CIEdu. Disponível em: https://pleiade.uniamerica.br/indez.php/pleiade/article/view/450/575).

CARVALHO, Luzia Alves de (A. PRINCIP.). Identidade institucional coletiva em tempos líquidos: possibilidade ou ilusão?. Rio de Janeiro: Usina de Letras, 2009.

CARVALHO, Luzia. Labirintos da pesquisa. Usina de letras. Rio de Janeiro, 2009.

CARVALHO, Luzia. $\quad$ Revista Pleiade (htpss://pleiade.uniamerica.br/index.php/pleiade/article/view/450/575)

CETIC. TIC Educação 2018: cresce interesse dos professores sobre o uso das tecnologias em atividades educacionais. Disponível: https://cetic.br/noticia/tic-educacao-2018-cresceinteresse-dos-professores-sobre-o-uso-das-tecnologias-em-atividades-educacionais/. Acesso em: 21 ago. 2019.

CHRISTENSEN, C.; HORN, M.; STAKER, H. Blended: usando a inovação disruptiva para aprimorar a educação. Tradução por Fundação Lemann e Instituto Península. 2015.

CRESCER, Instituto. APEI 50 - Avaliação de Práticas Educacionais Inovadoras. 2019

DELlAGNELO, Lúcia. Tecnologias fazem o vínculo de alunos com o cotidiano. O globo, sociedade p. 47. Publicado em 18 ago. 2019.

FREUD, S. A interpretação dos sonhos. 1996. Tradução de Wafredo Ismael de Oliveira. In: Obras Psicológicas Completas de Sigmund Freud. Rio de Janeiro, n. 423, p. 51, jun. 2006.

HORN, M. B.; STAKER, H. Blended: usando a inovação disruptiva para aprimorar a educação. Tradução: Maria Cristina Gularte Monteiro; revisão técnica: Adolfo Tanzi Neto, Lilian Bacich. Porto Alegre: Penso, 2015.

MORAN, José. Mudando a educação com metodologias ativas. Coleção Mídias Contemporâneas. Convergências Midiáticas, Educação e Cidadania: aproximações de jovens. v. II. 2015.

PERRENOUD, P. Construir as competências desde a escola. Artmed, 1999.

PPP. Projeto Político Pedagógico do CENSA. Rio de Janeiro, Campos dos Goytacazes. 2018

ROSA, J. G. Grande sertão: Veredas. 13. ed. Ed. Rio de Janeiro: J. Olympio, 1979.

SANTOS, Letícia. Educação 4.0: saiba como gestores e professores podem se preparar. In: INOVEDUC. Folha Dirigida. Edição 06, ano II, Out. 2018.

SOARES, J.C. Em busca de uma "razão sensível" no reino da cultura de massa. Mimeo. Logos. Comunicação e Universidade, UFRJ, Rio de Janeiro, 2002, vol. 9, n. 17, p. 7-18.

THIOLLENT, M. Metodologia da pesquisa-ação. 10. ed. São Paulo: Cortez, 2000.

Persp. Online: hum \& sociais aplicada., Campos dos Goytacazes, 26 (9) 32-51- 2019 seer.perspectivasonline.com.br 